\title{
Differential effects of health-promoting behaviors on wellbeing among adults
}

\author{
Valerie K. Blake · Abigail M. Nehrkorn · Julie H. Patrick
}

\begin{abstract}
As people age, identifying lifestyle choices that promote and support physical and emotional wellbeing becomes more important. Using the Reserve Capacity framework to explore psychosocial contributions to health disparities (Gallo, 2009), we examined the influences of age, gender, race, education, and income difficulty on engagement in two health-promoting behaviors: healthy eating and physical activity. We further examined how these factors relate to physical and emotional wellbeing in adults of varying ages. Data from 456 adults $(M$ age $=50.7)$ were used to test a model in which demographic variables, healthy eating and physical activity were expected to relate to both physical and emotional wellbeing. The model adequately fit the data $\left[\mathrm{x}^{2}(d f=47\right.$, $N=456)=150.57, p<.001 ; \mathrm{CFI}=.90$; TLI $=.84$; RMSEA $=.07$, accounting for $40.1 \%$ of the variance in physical wellbeing and $21.4 \%$ of the variance in emotional wellbeing. Physical activity directly influenced both physical and emotional wellbeing. Healthy eating related directly to emotional wellbeing, but not physical wellbeing. Race exerted neither direct nor indirect effects. Indirect effects of age on emotional wellbeing via healthy eating, and indirect effects of gender on both forms of wellbeing via physical activity were observed. Education was associated with physical wellbeing directly and indirectly, via physical activity. Education was indirectly associated with emotional wellbeing via healthy eating. Income difficulty exerted both direct effects on wellbeing and indirect effects via both health-promoting behaviors. The independent contribution of sociodemographic influences and the importance of looking beyond age, race and gender as correlates of wellbeing are discussed.
\end{abstract}

Keywords: wellbeing, health promotion, aging, health disparities

\section{Introduction}

Due to medical and other advances increasing survival through childhood and across the lifespan, people can expect to live longer now than at any other point in human history. Many adults, however, enter midlife being overweight and/or insufficiently physically active (Centers for Disease Control and Prevention [CDC], 2014), increasing the risk of chronic health conditions and disability (CDC, 2014; Mattson, 2014). Thus, a more complete picture of wellness in adulthood is needed. A variety of individual factors, behaviors and inequalities related to social status influence health and wellbeing at midlife (Camfield \& Skevington, 2008; Gallo, 2009). However, only a few studies have explicitly and simultaneously examined these interrelations (Hoyt, Chase-Lansdale, McDade, \& Adam, 2012; Lawton, Moss, Fulcomer, \& Kleban, 1982). The primary goal of the current study was to examine the influence of demographic and social status indicators on two modifiable health-promoting behaviors: healthy eating and physical activity, which, in turn, were hypothesized to influence physical and emotional wellbeing.

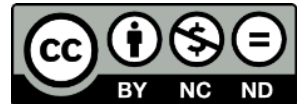

Copyright belongs to the author(s) www.internationaljournalofwellbeing.org 


\subsection{Wellbeing}

Wellbeing is a multifaceted and multidimensional construct, involving objective and subjective physical health, as well as cognitive and affective assessments of quality of life (Lawton, et al., 1982). Other conceptualizations, such as the PERMA model (Forgeard, Jayawickreme, Kern, \& Seligman, 2011; Seligman, 2011) focus on a wider range of dimensions, including positive emotions, engagement in meaningful activities, satisfying relationships with others, a life of meaning and purpose, and a sense of accomplishment. However, these aspects sometimes differ in their importance and interrelations at different points in the lifespan (Kern, Waters, Adler, \& White, 2015). Across varying conceptualizations of wellbeing in adulthood, however, the importance of both physical and emotional wellbeing emerges. A recent meta-analysis (Diener \& Chan, 2011) supports the links among emotional wellbeing, physical health and mortality risk, although other research points to more nuanced relations (Friedman \& Kern, 2014; La Placa, McNaught, \& Knight, 2013). Thus, disentangling the predictors of each form of wellbeing is an important public health initiative to promote health and wellbeing among adults.

Physical wellbeing often includes self-assessments of one's level of physical health and functional ability, as well as one's satisfaction with these areas (Lawton, et al., 1982). Emotional wellbeing incorporates cognitive and affective appraisals of a person's quality of life, based on individual values and expectations. Emotional wellbeing is often indexed through assessments of life satisfaction, affective experiences, and meaning. As indicators of current functioning and quality of life, these personal appraisals are often more meaningful to the individual than the clinical focus on morbidity and mortality (Diener, 2000; 2012). The extant literature in the field of aging and emotion presents a picture of increasing positive and decreasing negative affect across adulthood. Both men and women consistently report higher ratings for emotional wellbeing than physical wellbeing, but women report lower wellbeing than their male counterparts (Germain et al., 2013; Kostka \& Bogus, 2007).

\subsection{Health-promoting behaviors}

In the United States, guidelines for healthy eating and physical activity are the same across adulthood, although there are age-related differences in health behaviors. Current younger adults engage in more frequent leisure-time physical activity than other age groups (Schoenborn, Adams, \& Peregoy, 2013). Moreover, motivations to engage in physical activity may differ for adults of different ages (Gavin, Keough, Abravanel, Moudrakovski, \& Mcbrearty, 2014). Midlife, roughly ages 40 to 65 years, is a period when symptoms of illness and disability begin to emerge (Lachman, 2004). Thus, it is an ideal time to initiate compensatory lifestyle interventions to delay, minimize, or prevent age-related changes in physical and emotional functioning (Baltes, 1987). Among middle-aged and older adults, health promotion efforts often focus on increasing healthy eating and increasing physical activity because these behaviors tend to be highly modifiable and are associated with chronic health conditions and functional ability (Michie, Abraham, Whittington, McAteer, \& Gupta, 2009).

Public health initiatives often begin with education outreach, with a goal to increase knowledge regarding health promotion behaviors. Major initiatives have focused on helping the more than 35\% of American adults who are obese maintain healthy weight. Obesity is associated with increased risks for a host of chronic health conditions and depression (Ogden, Carroll, Kit, \& Flegal, 2012). Although greater knowledge of dietary recommendations among adults is associated with a higher intake of fruit and vegetables and lower intake of fats (Artinian, Fletcher, Mozaffarian, Kris-Etherton, Van Horn, Lichtenstein, et al., 2010), increasing knowledge may not be sufficient for improving or maintaining health. Similarly, knowledge regarding 
recommendations for physical activity is reasonably high among adults. A study of more than 2,000 adults showed that $94 \%$ recognized that regular exercise could result in health benefits and $68 \%$ knew the specific recommendations for physical activity. That knowledge, however, did not translate to increases in physical activity (Morrow, Krzewinski-Malone, Jackson, Bungum, \& Fitzgerald, 2004).

Despite the challenges associated with healthy eating and other health promotion behaviors, the benefits of positive behavioral change in a single area can be substantial, leading to broad improvements across multiple domains of functioning (Fisher et al., 2011). Thus, interventions that focus on a combination of healthy eating and increased physical activity have the most consistent record of improving physical and emotional wellbeing (Kostka \& Bogus, 2007; Maruf, Akinpelu, \& Salako, 2013; Michie et al., 2009).

\subsection{Individual differences}

Evidence shows that both physical and emotional wellbeing vary as a function of sociodemographic factors (CDC, 2014; Schoenborn et al., 2013), with early research focused almost exclusively on the interaction of age and race (Williams, Jackson \& Anderson, 1997). In the United States, racial health disparities are well known. As a group, African Americans often have poorer physical health than their Caucasian counterparts. Hispanic adults, regardless of race, also fare more poorly than Caucasians. Beyond race, other sociodemographic variables are also associated with wellbeing. For example, in both the Health and Retirement Study (HRS) (McLaughlin, Connell, Heeringa, Li, \& Roberts, 2010) and the National Health and Nutrition Examination Survey (NHANES) (Crimmins, Kim, \& Seeman, 2009), income and education emerge as primary influences on successful aging. Across nations, and even within wealthy nations like the United States, wealth is often associated with higher wellbeing (Diener \& Seligman, 2004). Although race is often used as a proxy, education (Raffensperger et al., 2010) and indicators of socioeconomic status (SES) may provide more specific information, with SES accounting for up to $60 \%$ of the "racial differences" in all-cause mortality (Thorpe et al., 2012). Of course, simply relying on measures of income is also inadequate (Diener \& Seligman, 2004). Thus, it is important to include a range of individual and sociodemographic factors.

The Reserve Capacity model posits that SES stratification of health-related outcomes reflects an unequal distribution of negative versus positive experiences throughout the lifespan (Gallo, 2009). According to this model, the conditions of low-SES environments expose individuals to more frequent stressful events (e.g., daily hassles, interpersonal conflict, discrimination), which can then negatively influence appraisals of and reactivity to future events. Over time, this increased stress-responding may deplete a person's resource reserves, leaving one vulnerable to negative physical and emotional outcomes (Gallo, 2009). Healthy eating and regular physical activity may offset these negative effects, thus ameliorating some of the negative outcomes associated with lifelong exposure to sociodemographic factors.

\subsection{The current study}

The current investigation sought to provide a better understanding of how individual characteristics are related to health-promoting behaviors and to wellbeing. The information gained can be utilized to aid in the design of effective interventions that are sensitive to the differential effects of health-promoting behaviors on wellbeing. Our analyses were guided by the model shown in Figure 1 below.

Although each path depicted represents a specific hypothesis based on the extant literature, the primary focus was on the roles of sociodemographic predictors of wellbeing and the roles 
that health-promoting behaviors might have. Thus, we anticipated that the two healthpromoting behaviors would covary (Amarantos et al., 2001; Kosta \& Bogus, 2007) and that each would be associated with both physical wellbeing and emotional wellbeing (Kosta \& Bogus, 2007; McAuley et al., 2000). Age, gender, race, level of education, and difficulty paying bills (income difficulty) were all expected to be associated with the extent of healthy eating, as indexed by adherence to nutrition guidelines and engaging in regular physical activity, and with levels of physical and emotional wellbeing (CDC, 2014).

Figure 1. Conceptual model in which each line represents a hypothesized relation between variables

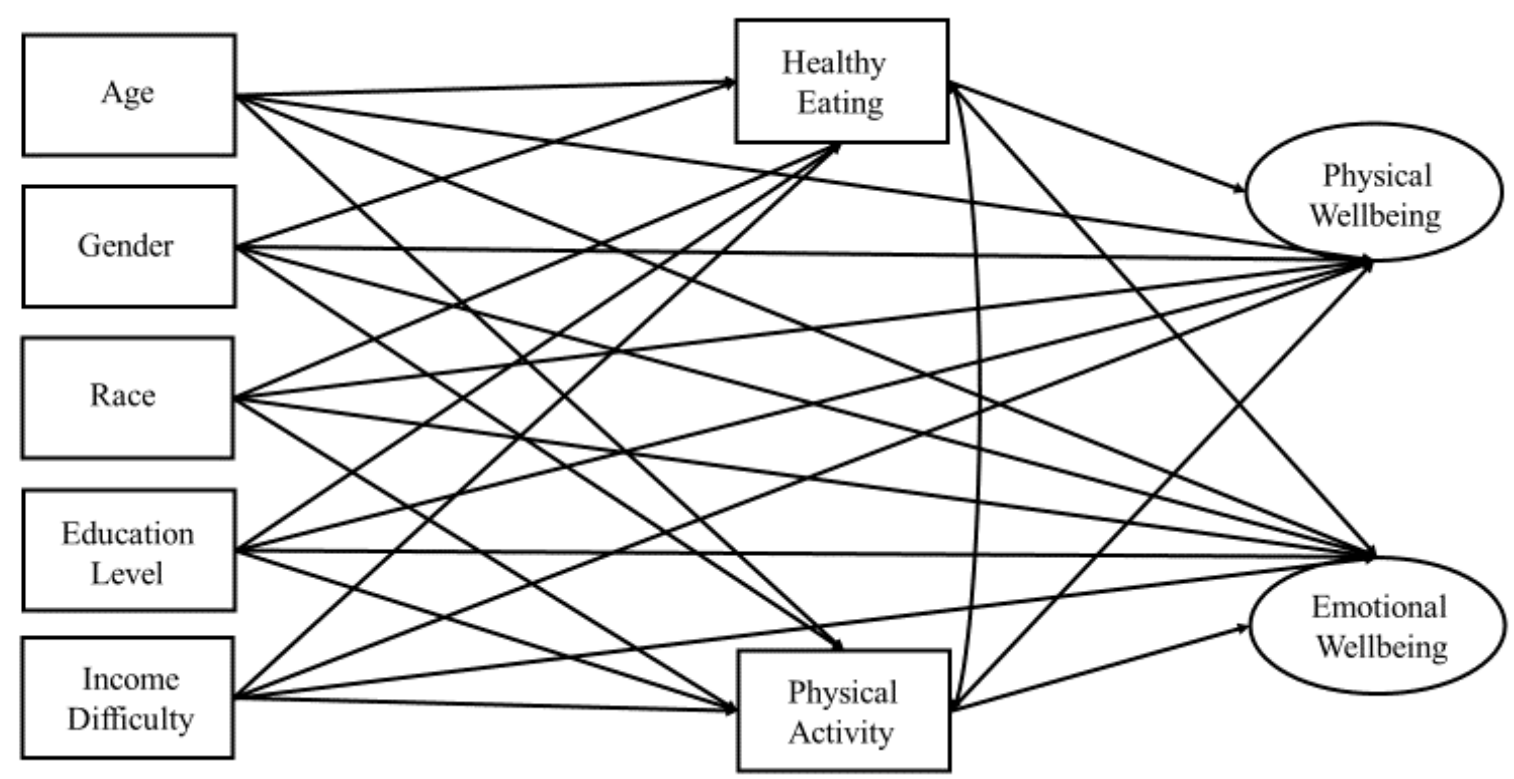

\section{Methods}

\subsection{Procedure}

Data for these analyses were gathered as part of a health literacy and health behaviors survey, which was approved by the affiliated institutional review board (IRB). Other, unrelated analyses from this sample have been reported elsewhere (Graf \& Patrick, 2014; Graf \& Patrick, 2015). In the spring of 2012, participants completed the survey as a human intelligence task (HIT) through Amazon Mechanical Turk (MTurk), an online crowd-sourcing service. Evidence suggests that MTurk samples are often equivalent to other forms of self-report surveys (Buhrmester, Kwang, \& Gosling, 2011; Johnson \& Borden, 2012; Weigold, Weigold, \& Russell, 2013). A total of 641 responses were collected. Each participant electronically consented prior to beginning the online survey and received a $\$ 5$ honorarium upon survey completion. As is common in online surveys (Oppenheimer, Meyvis, \& Davidenko, 2009), we included several response integrity items (e.g., asking age on page 1 and then date of birth on page 30, and asking participants to check a specific box for an integrity question). Responses from participants who failed more than three of these items were removed from the data set.

\subsection{Participants}

Of the 641 adults who consented, 126 were excluded from analyses because of missing more than $50 \%$ of the responses on the measures of interest. An additional 38 failed the response consistency 
items and 21 individuals did not identify as Caucasian, African American or Hispanic/no race specified. Thus, data from 456 adults were available for the current analyses.

Our sample was diverse in age, ranging from 18 to 85 years $(M$ age $=50.7$, SD $=11.97)$. Half of the respondents were female. The majority were married or partnered (59\%), although $7.9 \%$ were widowed, $13.6 \%$ divorced, and 19.3\% single/never married. About half (55\%) identified as Caucasian/White, 25.9\% identified as Black/African American, and 19.1\% were Hispanic/no race specified. The mean years of education completed was $14.4(\mathrm{SD}=1.9)$ years. Most $(98 \%)$ had completed high school, with $44.8 \%$ having earned a 4 -year or post-baccalaureate degree. Income difficulty varied, with $30.3 \%$ reporting no difficulty paying their bills, $32.9 \%$ having a little difficulty, $25 \%$ having some difficulty, and $11.8 \%$ reporting a great deal of difficulty paying their bills.

\subsection{Measures}

Health-promoting behaviors. The nine-item Nutrition subscale of the Health-Promoting Lifestyle Profile II (HPLP II) (Walker \& Hill-Polerecky, 1996; Stark, Chase \& DeYoung, 2010) was used to index healthy eating. Using a 4-point Likert-type scale, participants indicated the frequency with which they engaged in each behavior (never to routinely). Higher scores indicate healthier eating. The sample mean was $22.80(S D=5.04 ; \alpha=.81)$.

Using the same 4-point Likert-type scale that was used to measure healthy eating, we assessed physical activity with the eight-item Physical Activity subscale of the HPLP-II (Walker et al., 1996). The items query the frequency of following a planned exercise program, engaging in vigorous activity, and engaging in moderate physical activity. The sample mean was 18.67 (SD $=5.42 ; \alpha=.88)$.

Physical wellbeing. We used three indicators of physical wellbeing, including the single selfassessed global health item and two-item Physical Role Limitations subscale from the Medical Outcomes Study Short Form-12 Health Survey (MOS SF-12) (Ware, Kosinski, \& Keller, 1996). On average, our sample reported good to very good health $(M=3.40, S D=0.97)$ and few physical role limitations $(M=0.84, S D=1.25)$. We also used a modified version of the Philadelphia Geriatric Center's Multilevel Assessment Instrument (PGC-MAI) (Lawton et al., 1982). Because this scale includes a self-assessed global health item, we used its three unique items. The threeitem scale assesses problems performing ADLs, perception of health change, and health compared to peers. Higher scores represent better physical wellbeing. The mean of the threeitem scale was $5.81(S D=1.14 ; \alpha=.63)$.

Emotional wellbeing. The Philadelphia Geriatric Center (PGC) Positive and Negative Affect scales (Lawton, Kleban, Dean, Rajagopal, \& Parmelee, 1992) were used to assess emotional wellbeing. Each five-item scale includes the frequency of experiencing specific emotions during the previous week (never to very frequently), with higher scores representing more of the underlying construct. Positive affect includes the frequency of feeling happy, content, warmhearted, energetic, and interested. The mean for positive affect was $17.51(S D=3.36 ; \alpha=.79)$. Negative affect included the frequency of feeling annoyed, irritated, sad, worried, and depressed. For negative affect, a sample mean of $13.12(S D=4.16 ; \alpha=.87)$ was obtained. In addition, a single 7-point item assessing global happiness was used. The mean was $5.07(S D=1.31)$. 


\section{Results}

\subsection{Preliminary analyses}

Descriptive and bivariate statistics for demographic variables and scales are presented in Table 1 below. Pearson's coefficients are presented for continuous variables and Spearman's rho for categorical variables.

\subsection{Testing the model}

AMoS (V. 21) (Arbuckle, 2012) was used to estimate the model shown in Figure 2.

Figure 2. Final accepted model with standardized regression weights

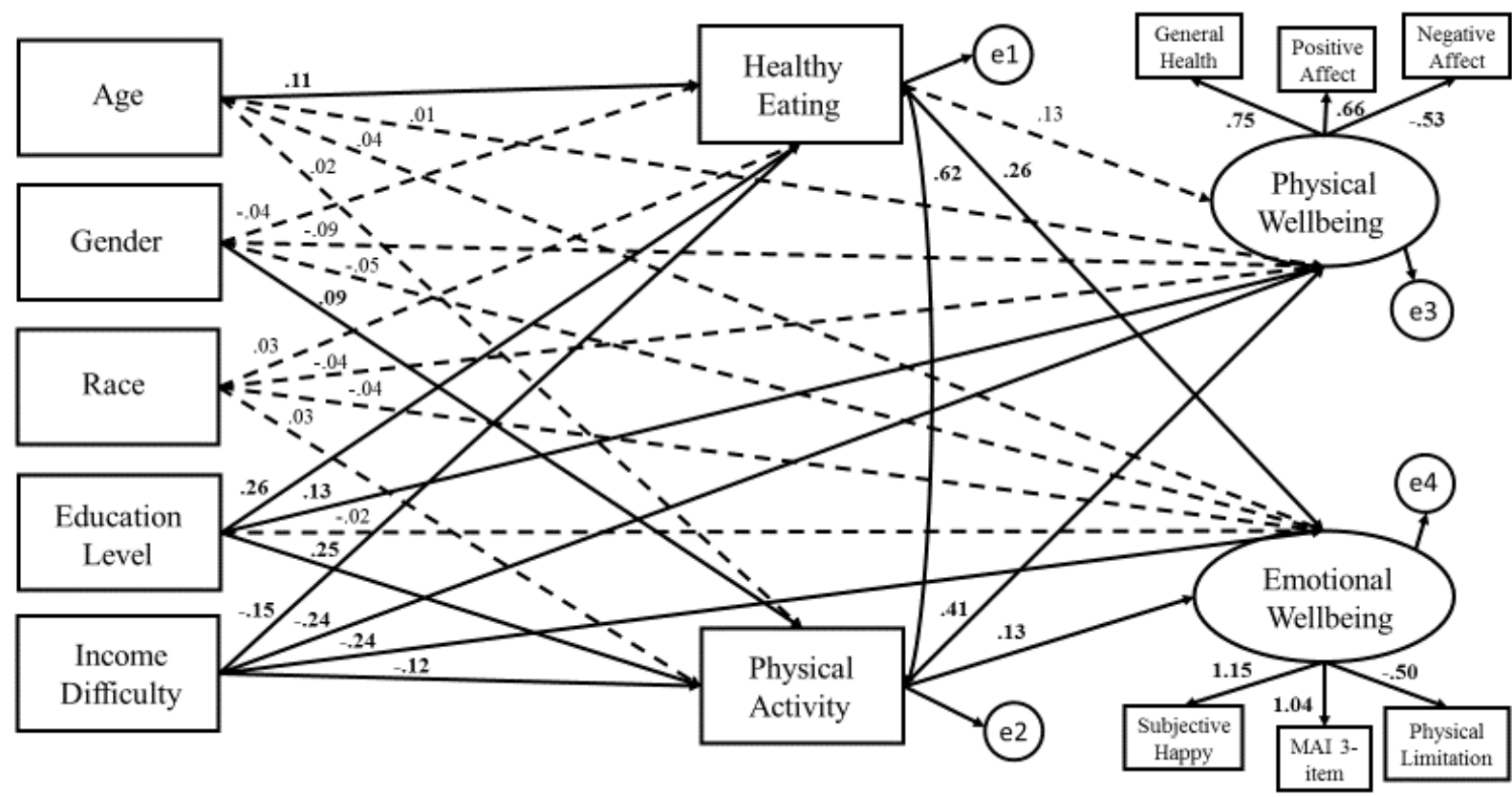

In determining statistical significance, standardized maximum likelihood estimates (MLE) were tested using the Critical Ratio ( $C R=$ MLE/Standard Error of the MLE). CRs greater than 1.96 are significant at the $p<.05$ level (Arbuckle, 2012; Byrne, 2010). We used multiple measures to assess model fit. In addition to the overall chi square, we used the Comparative Fix Index (CFI), the Tucker-Lewis Index (TLI), and the Root Mean Square Error Approximation (RMSEA) to assess model fit, using values greater than .90 as cutoffs for the CFI and TLI. For the RMSEA, values less than .08 indicate adequate fit, whereas values less than .05 indicate a good fit of the model to the data (Byrne, 2010). 
Table 1. Means, standard deviations, and correlations among model variables

\begin{tabular}{|c|c|c|c|c|c|c|c|c|c|c|c|c|c|}
\hline Variable & $M(S D)$ & 2 & 3 & 4 & 5 & 6 & 7 & 8 & 9 & 10 & 11 & 12 & 13 \\
\hline 1. Positive Affect & $\begin{array}{l}17.51 \\
(3.36)\end{array}$ & $-.55^{* *}$ & $.61^{* *}$ & $.31^{* *}$ & $-.18 * *$ & $.28 * *$ & $.28^{* *}$ & $.33^{* *}$ & .06 & -.04 & -.08 & $.13^{* *}$ & $-.23^{* *}$ \\
\hline 2. Negative Affect & $\begin{array}{l}13.12 \\
(4.16)\end{array}$ & -- & $-.46^{* *}$ & $-.25^{* *}$ & $.17^{* *}$ & $-.22^{* *}$ & $-.14^{* *}$ & $-.18^{* *}$ & $-.18^{* *}$ & -.03 & .06 & .001 & $.33^{* *}$ \\
\hline 3. Global Happy & $\begin{array}{c}5.07 \\
(1.31)\end{array}$ & & -- & $.35^{* *}$ & $-.12^{* *}$ & $.32 * *$ & $.29^{* *}$ & $.27^{* *}$ & $.11^{*}$ & -.01 & -.07 & $.12^{* *}$ & $-.32^{* *}$ \\
\hline 4. General Health & $\begin{array}{l}3.40 \\
(0.97)\end{array}$ & & & -- & $-.34^{* *}$ & $.59 * *$ & $.38^{* *}$ & $.28^{* *}$ & .01 & .04 & -.08 & $.20^{* *}$ & $-.24^{* *}$ \\
\hline 5. Role Limitations & $\begin{array}{c}0.84 \\
(1.25)\end{array}$ & & & & -- & $-.39 * *$ & $-.14 * *$ & $-.15^{* *}$ & -.04 & .07 & -.02 & $-.17^{* *}$ & $.23 * *$ \\
\hline 6. MAI 3-item scale & $\begin{array}{c}5.81 \\
(1.14)\end{array}$ & & & & & -- & $.39 * *$ & $.34^{* *}$ & .05 & -.02 & -.05 & $.23^{* *}$ & $-.25^{* *}$ \\
\hline 7. Healthy Eating & $\begin{array}{l}22.80 \\
(5.04)\end{array}$ & & & & & & -- & $.64^{* *}$ & $.15^{* *}$ & -.003 & -.05 & $.27^{* *}$ & $-.17^{* *}$ \\
\hline 8. Physical Activity & $\begin{array}{l}18.67 \\
(5.42)\end{array}$ & & & & & & & -- & .07 & $.11^{*}$ & -.03 & $.26^{* *}$ & $-.19^{* *}$ \\
\hline 9. Age & $\begin{array}{c}50.72 \\
(11.97)\end{array}$ & & & & & & & & -- & .01 & -.09 & .02 & $-.03^{* *}$ \\
\hline 10. Gender & 50\% Female & & & & & & & & & -- & .01 & .05 & $-.10^{*}$ \\
\hline 11. Race & 55\% White & & & & & & & & & & -- & $-.11^{*}$ & .06 \\
\hline 12. Education & $\begin{array}{l}14.35 \\
(1.86)\end{array}$ & & & & & & & & & & & -- & $-.12^{* *}$ \\
\hline 13. Income Difficulty & $\begin{array}{c}1.23 \\
(1.12) \\
\end{array}$ & & & & & & & & & & & & -- \\
\hline
\end{tabular}

Note. MAI $=$ Multilevel Assessment Instrument. ${ }^{*} p<0.05,{ }^{* *} p<0.01$ 
Following the recommended two-step approach (Anderson \& Gerbing, 1988), a measurement model was estimated. Results of the accepted measurement model $\left(x^{2}(d f=4, N=477)=7.48, p=\right.$ $.112 ; \mathrm{CFI}=.96 ; \mathrm{TLI}=.98 ; \mathrm{RMSEA}=.04)$ are presented in the upper portion of Table 2 .

Table 2. Standardized and unstandardized estimates for SEM Model

\begin{tabular}{|c|c|c|c|c|c|c|c|}
\hline \multicolumn{3}{|c|}{ Variable } & \multirow[t]{2}{*}{$\beta$} & \multirow[t]{2}{*}{$b$} & \multirow[t]{2}{*}{$S E(b)$} & \multirow[t]{2}{*}{$C R$} & \\
\hline \multicolumn{4}{|c|}{ Measurement Model } & & & & \\
\hline Subjective Happy & $\leftarrow$ & Emotional WB & .753 & 1.000 & & & \\
\hline Negative Affect & $\leftarrow$ & Emotional WB & -.534 & -2.244 & .352 & -6.379 & $* * *$ \\
\hline Positive Affect & $\leftarrow$ & Emotional WB & .664 & 2.235 & .255 & 8.759 & $* * *$ \\
\hline Global Health & $\leftarrow$ & Physical WB & 1.150 & 1.000 & & & \\
\hline Role Limitations & $\leftarrow$ & Physical WB & -.500 & -.617 & .163 & -3.775 & $* * *$ \\
\hline MAI 3-item scale & $\leftarrow$ & Physical WB & 1.041 & 1.591 & .187 & 8.495 & $* * *$ \\
\hline \multicolumn{8}{|l|}{ Structural Model } \\
\hline Physical Activity & $\leftarrow$ & Age & .022 & .010 & .020 & .501 & \\
\hline Healthy Eating & $\leftarrow$ & Age & .108 & .045 & .019 & 2.436 & * \\
\hline Emotional WB & $\leftarrow$ & Age & .039 & .003 & .004 & .815 & \\
\hline Physical WB & $\leftarrow$ & Age & .011 & .001 & .003 & .201 & \\
\hline Physical Activity & $\leftarrow$ & Gender & .089 & .961 & .482 & 1.992 & * \\
\hline Healthy Eating & $\leftarrow$ & Gender & -.039 & -.391 & .444 & -.880 & \\
\hline Emotional WB & $\leftarrow$ & Gender & -.054 & -.103 & .092 & -1.117 & \\
\hline Physical WB & $\leftarrow$ & Gender & -.094 & -.119 & .072 & -1.640 & \\
\hline Physical Activity & $\leftarrow$ & Education & .250 & .719 & .129 & 5.572 & *** \\
\hline Healthy Eating & $\leftarrow$ & Education & .260 & .697 & .119 & 5.869 & $* * *$ \\
\hline Emotional WB & $\leftarrow$ & Education & -.017 & -.009 & .025 & -.345 & \\
\hline Physical WB & $\leftarrow$ & Education & .134 & .045 & .020 & 2.266 & * \\
\hline Physical Activity & $\leftarrow$ & Income Difficulty & -.122 & -.587 & .216 & -2.716 & $* *$ \\
\hline Healthy Eating & $\leftarrow$ & Income Difficulty & -.154 & -.691 & .199 & -3.471 & $* *$ \\
\hline Emotional WB & $\leftarrow$ & Income Difficulty & -.238 & -.203 & .043 & -4.769 & $* * *$ \\
\hline Physical WB & $\leftarrow$ & Income Difficulty & -.239 & -.136 & .033 & -4.097 & $* * *$ \\
\hline Physical Activity & $\leftarrow$ & Race & .027 & .190 & .308 & .618 & \\
\hline Healthy Eating & $\leftarrow$ & Race & .028 & .172 & .284 & .605 & \\
\hline Emotional WB & $\leftarrow$ & Race & -.037 & -.045 & .058 & -.771 & \\
\hline Physical WB & $\leftarrow$ & Race & -.040 & -.032 & .046 & -.708 & \\
\hline Emotional WB & $\leftarrow$ & Physical Activity & .133 & .024 & .011 & 2.094 & * \\
\hline Physical WB & $\leftarrow$ & Physical Activity & .413 & .049 & .009 & 5.332 & $* * *$ \\
\hline Emotional WB & $\leftarrow$ & Healthy Eating & .256 & .049 & .012 & 3.915 & $* * *$ \\
\hline Physical WB & $\leftarrow$ & Healthy Eating & .125 & .016 & .010 & 1.648 & \\
\hline \multicolumn{3}{|c|}{ Covariance Healthy Eating Physical Activity } & .617 & 15.027 & 1.342 & 11.198 & $* * *$ \\
\hline
\end{tabular}

Physical wellbeing was indexed by three measures, including self-assessed global health and physical role limitations from the Medical Outcomes Study Short Form-12 Health Survey (Ware 
et al., 1996) and the PGC-MAI index of functional ability (Lawton et al., 1982). Emotional wellbeing was indexed using three measures, including a global happiness assessment, and the positive and negative affect scales (Lawton et al., 1992). Each measure loaded onto its hypothesized construct.

Results of the path model are shown in the bottom portion of Table 2 above. The summary statistics suggested acceptable fit of the model to the data $\left(x^{2}(d f=47, N=456)=150.57, p<.001\right.$; $\mathrm{CFI}=.90 ; \mathrm{TLI}=.84 ; \mathrm{RMSEA}=.07)$. The model accounted for $40.1 \%$ of the variance in physical wellbeing and $21.4 \%$ of the variance in emotional wellbeing. Approximately $10.5 \%$ of the variance in healthy eating and $8.6 \%$ of the variance in physical activity was explained by the five sociodemographic variables.

As shown in Table 2 above, each individual path was assessed for significance. Only half of these paths reached statistical significance. More physical activity $(\beta=.13)$, healthier eating $(\beta=$ $.26)$, and less income difficulty $(\beta=-.24)$ were associated with better emotional wellbeing. Physical wellbeing was directly influenced by more physical activity $(\beta=.41)$, less income difficulty $(\beta=-.24)$, and more education $(\beta=.13)$. Similarly, age $(\beta=.11)$, less income difficulty $(\beta$ $=-.15)$, and more education $(\beta=.26)$ were associated with healthier eating. Physical activity was associated with male gender $(\beta=.09)$, less income difficulty $(\beta=-.12)$, and more years of education $(\beta=.25)$. As expected, the two health promotion behaviors were highly correlated ( $\beta$ $=.62)$.

\subsection{Total, direct and indirect effects}

In order to achieve a better understanding of the ways in which demographic variables influence wellbeing, we conducted a closer examination of these paths for direct and indirect associations among variables in the model (see Table 3).

Table 3. Direct and indirect effects among model variables and physical and emotional wellbeing

\begin{tabular}{llccc}
\hline \multirow{2}{*}{ Outcome } & Determinant & \multicolumn{3}{c}{ Causal Effects $(\beta)$} \\
\cline { 2 - 4 } & & Direct & Indirect & Total \\
\hline Physical Wellbeing & Healthy Eating & .125 & - & .125 \\
$\left.\mathrm{r}^{2}=.40\right)$ & Physical Activity & .413 & -- & .413 \\
& Age & .011 & .023 & .034 \\
& Gender & -.094 & .032 & -.062 \\
& Education & .134 & .136 & .270 \\
& Income Difficulty & -.239 & -.070 & -.308 \\
Emotional Wellbeing & Race & -.040 & .015 & -.025 \\
$\left(\mathrm{r}^{2}=.21\right)$ & Healthy Eating & .256 & - & .256 \\
& Physical Activity & .133 & -- & .133 \\
& Age & .039 & .031 & .070 \\
& Gender & -.054 & .002 & -.052 \\
& Education & -.017 & .100 & .083 \\
& Income Difficulty & -.238 & -.056 & -.293 \\
& Race & -.037 & .011 & -.026 \\
\hline
\end{tabular}

Note. ${ }^{*} p<.05 .{ }^{* *} p<.01 .{ }^{* * *} p<.001$ 


\section{Discussion}

Wellbeing may be improved through specific behaviors, including healthy eating and physical exercise (Kostka \& Bogus, 2007). However, many adults do not engage in optimal levels of either of these health-promoting behaviors. Identifying which demographic characteristics are most associated with healthy behaviors may advance our ability to improve wellbeing across the lifespan (Olson et al., 2014). To that end, the current study examined the relations among individual characteristics, health-promoting behaviors, and physical and emotional wellbeing in adults. The resulting model accounted for $40 \%$ of the variance in physical wellbeing and $21 \%$ of the variance in emotional wellbeing. The primary hypotheses, wherein adherence to healthy eating guidelines and engaging in physical activity relate to better wellbeing, were generally supported.

The expected relation between healthy eating and higher emotional wellbeing emerged as significant, although modest. The modest strength of this association seems appropriate, however, due to the multiple dimensions comprising emotional wellbeing. Further, the nonsignificant association between healthy eating and physical wellbeing may reflect delayed effects of healthy eating on physical wellbeing, requiring longitudinal analyses for detection (Germain et al, 2013). It is also conceivable that healthy eating and physical wellbeing are reciprocally related, such that physical health prompts healthy dietary choices, which, in turn, support continued physical health. Longitudinal data are better suited to answering questions about temporal ordering of effects.

Engaging in physical activity was significantly related to both physical and emotional wellbeing in the model, replicating associations found in previous literature (Fisher et al., 2011; Kostka \& Bogus, 2007; McAuley et al., 2000; Stahl \& Patrick, 2012). Although the strength of the relation between physical activity and physical wellbeing is stronger, the association between physical activity and emotional wellbeing also has practical importance (McAuley et al., 2000; Olson et al., 2014). By investigating both paths in the same model, we address the differential effects of physical activity on multiple dimensions of wellbeing.

According to the Reserve Capacity model, it is important to understand how individual and demographic characteristics relate to personal resources in order to support health and healthpromoting behavior (Gallo, 2009). Education and income difficulty were each directly, albeit modestly, associated with physical wellbeing. Closer inspection of each path revealed additional indirect influences of education and income difficulty on physical wellbeing, through their relation with physical activity. Thus, by studying the various demographic variables, such as gender and education, we can better understand how these variables influence physical activity and overall wellbeing. Physical activity and wellness may contribute to a variety of positive or negative outcomes, significantly impacting one's health.

Although we had also hypothesized direct associations between emotional wellbeing and each demographic variable, only income difficulty emerged, and its effects were much stronger than expected in this online sample of adults. This result may reflect different motives for technology use in this MTurk sample, such that those with the highest SES are engaging online because they have free time and wish to be connected to an online community, whereas those with middle SES are online in order to supplement their income. Adherence to healthy eating guidelines was also directly related to increased emotional wellbeing. Examination of indirect effects reveals the additional influence of greater educational attainment and less income difficulty on emotional wellbeing, through their influence on better adherence to guidelines for healthy eating. Parsing-out each specific avenue of influence on the physical and emotional 
wellbeing of adults thus reveals the complex relations among personal characteristics, social environment, and lifestyle behaviors that place some individuals at risk for negative outcomes.

In terms of health-promoting behavior, older age, more education, and ability to pay one's bills predicted healthy eating among these adults. Similarly, those with more education and those who can pay their bills were more likely to engage in regular physical activity. Although not directly associated with either outcome, age did exert modest indirect effects on greater emotional wellbeing through healthy eating. This may be due to the fact that these relatively young, middle-aged and older adults may not yet be experiencing health issues that have prompted engagement in health-promoting behaviors in other samples (Olson et al., 2014; Stahl \& Patrick, 2012).

Education showed a strong relationship with both health-promoting behaviors, even within a sample that was highly educated. Participants with more education experienced greater physical wellbeing via more frequent participation in physical activity and greater emotional wellbeing indirectly through better eating behaviors. These results indicate that higher education may contribute to understanding the importance of following empirically-based guidelines for healthy eating and physical activity, resulting in increased engagement in these behaviors.

Income difficulty, then, evidenced similarly sized but opposite effects among these variables. Participants who were more financially strained were also less likely to engage in regular physical activity, indirectly affecting already lowered physical wellbeing. An indirect effect of income difficulty on emotional wellbeing is also evidenced through eating behavior, suggesting that income difficulty is not only physically and emotionally distressing, but is also associated with limited engagement in health promotion. These results further lend support to the Reserve Capacity model, whereby those with more education have experienced less financial strain and therefore have more resources available to attend to health-promoting behaviors. Thus, just as in the case of age, gender, and race, potentially significant influences on wellbeing may be obscured in investigations that fail to deconstruct the influence of social status (Ball, Mishra, \& Crawford, 2003).

\subsection{Limitations and future directions}

Although this study has both theoretical and practical significance, there are several limitations to be considered when interpreting these data. First, these data were based solely on self-reported dietary and physical activity behaviors. Self-report data have several benefits, including being relatively inexpensive and anonymous. The most common disadvantages are response biases, wherein the participants' responses are affected by social desirability and expectations; and cognitive fatigue and memory burden, affecting the validity of their responses (Paulhas \& Vazire, 2007). The current study was designed to reduce these effects while optimizing efficiency of data collection.

Although cross-sectional analyses limit assumptions of causality, logic and theory indicate reciprocal relations. As a snapshot of a dynamic process, we cannot declare unequivocally that the hypothesized direction of influence is appropriate, although our post hoc analyses lend support to our model. Longitudinal studies can more fully disentangle the reciprocal associations among personal characteristics, health-promoting behaviors, physical wellbeing, and emotional wellbeing. Cross-sectional evaluations of subjective wellbeing are, however, a valid representation of an individual's current state of functioning within their current environment (Diener, 2000).

One important aspect of this study was the use of the internet for data collection. This method of data collection has several potential benefits for the researcher, including reducing the costs 
and time involved in data collection, and access to larger, more diverse samples, especially historically hard-to-reach populations. Online surveys are also user-friendly and convenient for participants (Buhrmester et al., 2011). Potential problems include selection bias, limiting samples to only those with internet access, and loss of clarification due to the lack of contact with the researcher (Casler, Bickel, \& Hackett, 2013). However, MTurk has been found to be less biased than other internet samples, as well as many university samples (Buhrmester et al., 2011; Casler et al., 2013). As online data collection has increased in popularity, many questions regarding data equivalence have been raised.

Ensuring continued wellbeing through life is a priority for individuals, their families, and the health care system. Identifying the mechanisms through which we can increase wellbeing in the aging population is the first step toward achieving this goal. The current investigation extends the literature, supporting the value of healthy eating and physical activity as lifestyle components, which support and promote positive ratings of physical and emotional wellbeing in young, middle-aged and older adults. Furthermore, the strong influence of demographic variables on health-promoting behaviors and on physical and emotional wellbeing accentuate the importance of identifying specific sources of health inequalities, in order to better identify those at higher risk and those who might benefit most from interventions.

\section{Authors}

Valerie K. Blake

West Virginia University

Abigail M. Nehrkorn

West Virginia University

Julie Hicks Patrick

West Virginia University

Julie.Patrick@mail.wvu.edu

\section{Publishing Timeline}

Received 21 September 2015

Accepted 12 July 2017

Published 25 November 2017

\section{References}

Amarantos, E., Martinez, A., \& Dwyer, J. (2001). Nutrition and quality of life in older adults. Journals of Gerontology: SERIES A, 56A, 54-64. http://dx.doi.org/10.1093/gerona/56.suppl 2.54

Anderson, J. C., \& Gerbing, D. W. (1988). Structural equation modeling in practice: A review and recommended two-step approach. Psychological Bulletin, 103(3), 411. https://doi.org/10.1037/00332909.103.3.411

Arbuckle, J. L. (2012). Amos 21 reference guide. Chicago, IL: SmallWaters.

Artinian, N. T., Fletcher, G. F., Mozaffarian, D., Kris-Etherton, P., Van Horn, L., Lichtenstein, A. H., ... \& Meininger, J. C. (2010). Interventions to promote physical activity and dietary lifestyle changes for cardiovascular risk factor reduction in adults: A scientific statement from the American Heart Association. Circulation, 122, 406-441. http://dx.doi.org/10.1161/CIR.0b013e3181e8edf1

Ball, K., Mishra, G. D., \& Crawford, D. (2003). Social factors and obesity: An investigation of the role of health behaviours. International Journal of Obesity, 27(3), 394-403.

http://dx.doi.org/10.1038/sj.ijo.0802237 
Baltes, P. (1987). Theoretical propositions of life-span developmental psychology: On the dynamics between growth and decline. Developmental Psychology, 23(5), 611-626. http://dx.doi.org/10.1037/0012$\underline{1649.23 .5 .611}$

Buhrmester, M., Kwang, T., \& Gosling, S. D. (2011). Amazon's Mechanical Turk: A new source of inexpensive, yet high-quality, data? Perspectives on Psychological Science, 6(1), 3-5. http://dx.doi.org/10.1177/1745691610393980

Byrne, B. M. (2010). Structural equation modeling with AMOS. (2nd ed.). New York, NY: Routledge.

Camfield, L., \& Skevington, S. M. (2008). On subjective well-being and quality of life. Journal of Health Psychology, 13(6), 764-775. https://doi.org/10.1177/1359105308093860

Casler, K., Bickel, L., \& Hackett, E. (2013). Separate but equal? A comparison of participants and data gathered via Amazon's MTurk, social media, and face-to-face behavioral testing. Computers in Human Behavior, 29(6), 2156-2160. https://doi.org/10.1016/j.chb.2013.05.009

Centers for Disease Control and Prevention. (2014). Division of nutrition, physical activity, and obesity. http://www.cdc.gov/nccdphp/dnpao/index.html

Crimmins, E. M., Kim, J. K., \& Seeman, T. E. (2009). Poverty and biological risk: The earlier "aging" of the poor. The Journals of Gerontology Series A: Biological Sciences and Medical Sciences, 64(2), 286-292. http://dx.doi.org/10.1093/gerona/gln010

Diener, E. (2000). Subjective wellbeing: The science of happiness and a proposal for a national index. American Psychologist, 55(1), 34-43. http://dx.doi.org/10.1037//0003-066x.55.1.34

Diener, E. (2012). New findings and future directions for subjective wellbeing research. American Psychologist, 67(8), 590-597. http://dx.doi.org/10.1037/a0029541

Diener, E., \& Chan, M. Y. (2011). Happy people live longer: Subjective wellbeing contributes to health and longevity. Applied Psychology: Health and Wellbeing, 3(1), 1-43. http://dx.doi.org/10.1111/j.17580854.2010.01045.x

Diener, E., \& Seligman, M. E. P. (2004). Beyond money: Toward an economy of well-being. Psychological Science in the Public Interest, 5, 1-31. https://doi.org/10.1111/j.0963-7214.2004.00501001.x

Fisher, E. B., Fitzgibbon, M. L., Glasgow, R. E., Haire-Joshu, D., Hayman, L. L., Kaplan, R. M., Nanney, M. S., \& Ockene, J. K. (2011). Behavior matters. American Journal of Preventive Medicine, 40(5), e15-e30. http://dx.doi.org/10.1016/j.amepre.2010.12.031

Forgeard, M. J., Jayawickreme, E., Kern, M. L., \& Seligman, M. E. (2011). Doing the right thing: Measuring wellbeing for public policy. International Journal of Wellbeing, 1(1), 79-106.

Friedman, H. S., \& Kern, M. L. (2014). Personality, well-being, and health. Annual Review of Psychology, 65, 719-742. https://doi.org/10.1146/annurev-psych-010213-115123

Gallo, L. C. (2009). The Reserve Capacity Model as a framework for understanding psychosocial factors in health disparities. Applied Psychology: Health and Wellbeing, 1(1), 62-72. https://doi.org/10.1111/j.1758-0854.2008.01000.x

Gavin, J., Keough, M., Abravanel, M., Moudrakovski, T., \& Mcbrearty, M. (2014). Motivations for participation in physical activity across the lifespan. International Journal of Wellbeing, 4(1), 46-61. http://dx.doi.org/10.5502/ijw.v4i1.3

Germain, L., Latarche, C., Kesse-Guyot, E., Galan, P., Hercberg, S., \& Briancon, S. (2013). Does compliance with nutrition guidelines lead to healthy aging? A quality-of-life approach. Journal of the Academy of Nutrition and Dietetics 113(2), 228-240.

Graf, A. S., \& Patrick, J. H. (2014). The influence of sexual attitudes on mid- to late life sexual well-being: Age, not gender, as a salient factor. International Journal of Aging and Human Development, 79, 55-79. https://doi.org/10.2190/AG.79.1.C

Graf, A. S., \& Patrick, J. H. (2015). Foundations of life-long sexual health literacy. Health Education, 115(1), 56-70. https://doi.org/10.1108/HE-12-2013-0073

Hoyt, L. T., Chase-Lansdale, P. L., McDade, T. W., \& Adam, E. K. (2012). Positive youth, healthy adults: Does positive well-being in adolescence predict better perceived health and fewer risky health behaviors in young adulthood? Journal of Adolescent Health, 50(1), 66-73.

https://doi.org/10.1016/j.jadohealth.2011.05.002 
Johnson, D. R., \& Borden, L. A. (2012). Participants at your fingertips: Using Amazon's Mechanical Turk to increase student-faculty collaborative research. Teaching of Psychology, 39(4), 245-251. http://dx.doi.org/10.1177/0098628312456615

Kern, M. L., Waters, L. E., Adler, A. \& White, M. A. (2015). A multidimensional approach to measuring well-being in students: Application of the PERMA framework. The Journal of Positive Psychology, 10, 262-271. https://doi.org/10.1080/17439760.2014.936962

Kostka, T., \& Bogus, K. (2007). Independent contribution of overweight/obesity and physical activity to lower health-related quality of life in community-dwelling older subjects. Zeitschrift für Gerontologie und Geriatrie, 40, 43-51. http://dx.doi.org/10.1007/s00391-006-0374-6

Lachman, M. E. (2004). Development in midlife. Annual Review of Psychology, 55, 305-331. http://dx.doi.org/10.1146/annurev.psych.55.090902.141521

La Placa, V., McNaught, A., \& Knight, A. (2013). Discourse on wellbeing in research and practice. International Journal of Wellbeing, 3(1), 116-125. http://dx.doi.org/10.5502/ijw.v3i1.7

Lawton, M. P., Kleban, M. H., Dean, J., Rajagopal, D., \& Parmelee, P. A. (1992). The factorial generality of brief positive and negative affect measures. Journal of Gerontology: Psychological Sciences, 47, $228-237$. http://dx.doi.org/10.1093/geronj/47.4.P228

Lawton, M. P., Moss, M., Fulcomer, M., \& Kleban, M. H. (1982). A research and service oriented multilevel assessment instrument. Journal of Gerontology, 37(1), 91-99. http://dx.doi.org/10.1093/geronj/37.1.91

Maruf, F. A., Akinpelu, A. O., \& Salako, B. L. (2013). Self-reported quality of life before and after aerobic exercise training in individuals with hypertension: A randomized-controlled trial. Journal of Applied Psychology: Health and Well-Being, 5(2), 209-224. http://dx.doi.org/10.1111/aphw.12005

Mattson, M. P. (2014). The challenge of optimal brain health throughout life. New York: NY: Syracuse University Aging Studies Institute.

McAuley, E., Blissmer, B., Marquez, D. X., Jerome, G. J., Kramer, A. F., \& Katula, J. (2000). Social relations, physical activity, and wellbeing in older adults. Preventive Medicine, 31, 608-617. http://dx.doi.org/10.1006/pmed.2000.0740

McLaughlin, S. J., Connell, C. M., Heeringa, S. G., Li, L. W., \& Roberts, J. S. (2010). Successful aging in the United States: Prevalence estimates from a national sample of older adults. Journals of Gerontology, Series B: Psychological Sciences and Social Sciences, 65B(2), 216-226. http://dx.doi.org/10.1093/geronb/gbp101

Michie, S., Abraham, C., Whittington, C., McAteer, J., \& Gupta, S. (2009). Effective techniques in healthy eating and physical activity interventions: A meta-regression. Health Psychology, 28(6), 690-701.

Morrow, J. R., Jr., Krzewinski-Malone, J. A., Jackson, A. W., Bungum, T. J., \& Fitzgerald, S. J. (2004). American adults' knowledge of exercise recommendations. Research Quarterly for Exercise and Sport, 75(3), 231-237. http://dx.doi.org/10.1080/02701367.2004.10609156

Ogden, C. L., Carroll, M. D., Kit, B. K., \& Flegal, K. M. (2012). Prevalence of obesity in the United States, 2009-2010. https://www.cdc.gov/nchs/data/databriefs/db82.pdf

Olson, E. A., Fanning, J. T., Awick, E. A., Chung, H. D., \& McAuley, E. (2014). Differential trajectories of wellbeing in older adult women: The role of optimism. Applied Psychology: Health and Wellbeing, 6(3), 362-380. http://dx.doi.org/10.1111/aphw.12033

Oppenheimer, D. M., Meyvis, T., \& Davidenko, N. (2009). Instructional manipulation checks: Detecting satisficing to increase statistical power. Journal of Experimental Social Psychology, 45(4), 867-872. http://dx.doi.org/10.1016/j.jesp.2009.03.009

Paulhus, D. L., \& Vazire, S. (2007). The self-report method. Handbook of Research Methods in Personality Psychology, 1, 224-239.

Raffensperger, S., Kuczmarski, M. F., Hotchkiss, L., Cotugna, N., Evans, M. K., Zonderman, A. B. (2010). Effect of race and predictors of socioeconomic status on diet quality in the HANDLS Study sample. Journal of the National Medical Association, 102(10), 923-930. https://doi.org/10.1016/S00279684(15)30711-2

Schoenborn, C. A., Adams, P. F., \& Peregoy, J. A. (2013). Health behaviors of adults: United States, 20082010. Vital and health statistics: Series 10, Data from the National Health Survey, (257), 1-184. 
Seligman, M. (2011). Flourish. New York, NY: Simon \& Schuster.

Stahl, S. T., \& Patrick, J. H. (2012). Adults' future time perspective predicts engagement in physical activity. Journals of Gerontology Series B: Psychological Sciences and Social Sciences, 67(4), 413-416. https://doi.org/10.1093/geronb/gbr118

Stark, M. A., Chase, C., \& DeYoung, A. (2010). Barriers to health promotion in community dwelling elders. Journal of Community Health Nursing, 27(4), 175-186.

https://doi.org/10.1080/07370016.2010.515451

Thorpe, R. J., Jr., Koster, A., Bosma, H., Harris, T. B., Simonsick, E. M., van Eijk, J. T. M., ... \& Kritchevsky, S. B. (2012). Racial differences in mortality in older adults: Factors beyond socioeconomic status. Annals of Behavioral Medicine, 43(1), 29-38. http://dx.doi.org/10.1007/s12160-011-9335-4

Walker, S. N. \& Hill-Polerecky, D. M. (1996). Psychometric evaluation of the Health-Promoting Lifestyle Profile II. (Unpublished manuscript). University of Nebraska Medical Center.

Ware, J. E., Jr., Kosinski, M., \& Keller, S. D. (1996). A 12-item short-form health survey: Construction of scales and preliminary tests of reliability and validity. Medical Care, 34(3), 220-233. http://dx.doi.org/10.1097/00005650-199603000-00003

Weigold, A., Weigold, I. K., \& Russell, E. J. (2013). Examination of the equivalence of self-report surveybased paper-and-pencil and internet data collection methods. Psychological Methods, 18(1), 53-70. https://doi.org/10.1037/a0031607

Williams, D. R., Yu, Y., Jackson, J. S., \& Anderson, N. B. (1997). Racial differences in physical and mental health: Socio-economic status, stress and discrimination. Journal of Health Psychology, 2(3), 335-351. https://doi.org/10.1177/135910539700200305 